\title{
Ellipsis
}

2021

\section{Lesbians are the Real Blood Suckers: Exploring Homosexuality and Vampirism through The Gilda Stories}

Jacia Carlile

Follow this and additional works at: https://scholarworks.uno.edu/ellipsis

\section{Recommended Citation}

Carlile, Jacia (2021) "Lesbians are the Real Blood Suckers: Exploring Homosexuality and Vampirism through The Gilda Stories," Ellipsis: Vol. 46, Article 21.

DOI: https://doi.org/10.46428/ejail.46.21

Available at: https://scholarworks.uno.edu/ellipsis/vol46/iss1/21

This Essay is brought to you for free and open access by the Department of English and Foreign Languages at ScholarWorks@UNO. It has been accepted for inclusion in Ellipsis by an authorized editor of ScholarWorks@UNO. For more information, please contact scholarworks@uno.edu. 


\section{Catherine B. Mackin Prize Winner}

\section{Lesbians are the Real Blood Suckers: Exploring Homosexuality and Vampirism through The Gilda Stories by Jacia Carlile}

What does a female homosexual and a blood sucking demon have in common? Why, that they subvert the hegemony of the patriarchy, of course! Vampires have been used to tell tales of female homosexuality as early as 1871 when Joseph Sheridan Le Fanu published Carmilla. Through the act of literally demonizing lesbians in the novella, Le Fanu unintentionally provided a set up for lesbian women to self-identify with and create their own vampires. Lesbians began to reclaim the title of vampire, writing literature in masses that took on the narrative of the "other" and turned all stereotypes on their heads. One such novel became a hit among black female, lesbian, and goth communities - The Gilda Stories by Jewelle Gomez. It is a revolutionary classic for its reconciliation of vampires with minority identities. The Gilda Stories can be used to show important lesbian intersectional feminist themes, through the exploration of blood in vampirism, how vampirism plays into Gilda's character, and Gomez's use of reclamation to subvert harmful stereotypes.

Monsters in fiction are written for any number of reasons, and each monster trope evolves with time and culture. Some monsters represent cruel dictators, others are used as warning against taboo behavior, and still others tell histories through folklore (Halberstam 125). Vampires have evolved greatly throughout history, being a popular monster figure in stories even before Bram Stoker's Dracula was ever published. The vampire, and particularly the vampiric act of blood drinking, has been used throughout time as a metaphor for everything from economic issues to tampons (Parker 1-66). Carmilla, for example, is arguably a cautionary tale for men surrounding menstruation and the assumed susceptibility of women to break taboo (Case 7).

The difference between the "other" and the "normal" has a very narrow margin to begin with, as the "other" originates from within the "normal" and is subject to change with social conditions. Monsters can be found as both the distant "other" and as part of that normal within, allowing the interplay of binary opposition (Cohen 15). One common binary opposition - one of the binaries that create the vampire metaphor in the first place - is that of the life/death binary. The boundaries of life and death are hard ones, life being of nature and goodness, and death being a queer and supernatural state (Case 3 ).

Immediately in the realm of monsters, one can see where the breakdown of the life/death binary begins. Vampires are all at once dead and undead - a corpse re-animated and representative of both the human and of what the human fears. Through expressions of hunger, jealousy, salaciousness, and other human emotions, the vampire becomes just the same as any other human, with the sole exception of being unnatural (Cohen 27). That exception is mitigated when comparing the vampire to a human deemed unnatural in a similar sense. The monster becomes less human to the majority of the audience, yet increasingly human to those who are themselves outside of the majority. This is where we see vampires as a reflection of 
homosexuality. Capturing this reflection, lesbian authors, such as Jewelle Gomez, put pen to paper and began their own tradition of homosexual vampires.

In The Gilda Stories, the second Gilda, whom we follow throughout the book, does not begin to have a life - an existence on her own terms, with her own enacted decisions and independence - until the first Gilda turns her into a member of the undead. This is an abnormal thought, generally: those who are killed should not have a more fulfilling life now than when they were alive. However, this does not apply to Gilda in her narrative. Gomez says of her character, "In Gilda, I created a character who escapes from her deep sense of helplessness as a slave and gains the ultimate power over life and death" (Gomez XII). In this way, vampires, while still blood-sucking parasites that dwell in the realm beyond normal, can begin to transform into beings of empowerment for homosexuals, lesbians in particular.

There is more than one answer to the first question asked, "What does a female homosexual and a blood sucking demon have in common?" Beyond the connections of lesbianism and minority status, this question begs an explanation on how women are associated (or not associated) with blood. In vampire lore, there is an emphasis on bloodsucking as a way of taking life - blood in association with violence, the stories overwrought with gory imagery and death (Parker 40). Even generally, blood is a signifier of violence, with descriptions of blood paramount to war stories and other atrocities. In contrast, the only blood that signifies giving life, as opposed to violence and attempts to take it, is a woman's monthly cycle. Despite this power that menstruation allows women, it is still associated with uncleanliness. Some of the symptoms of menstruation are similar to female vampires, both as written by men and by women - men associating the vampires to paleness/weakness and the sapping of men's lives and livelihoods, women associating the vampires with reclaimed sexuality and freedom once she no longer relies on men (Parker 1-44).

Through this equating of blood to life, blood drinking also becomes the act of creating life - sex. Vampires already blur the lines between life and death with their existence, but it goes further with their unnatural procreation. In vampire novels, the sex alluded to is specifically taboo - sex that does not have the capability of creating life - while the vampire character is a stand-in for the lustful seducer (Parker 18). A female in the role of the deviant seducer is established in The Gilda Stories and doubled through the introduction of other female vampires or through Gilda's seduction of other, now deviant, women. However, Gilda does not turn every person that she takes blood from. In conservative thought, sex is only for procreation. This makes homosexual activities parasitic - wasteful, pathological, exhaustive, and existing outside of the marriage contract (Halberstam 133). Gilda drinking blood—a metaphor for having sex through penetrating others - without turning the person she drinks from is the equivalent of having queer sex, where creating life is not the central point, therefore it falls on the death side of the life/death binary, where the uncanny lies.

The Gilda Stories places vampires mostly in the death side of the binary, but through her birth through two mothers, Gilda finds herself breaking the boundaries into queer sex equating life. First, it is important to examine where said boundaries lie.

Dracula of Dracula and Carmilla of Carmilla are both examples of arguably or explicitly homosexual vampires. However, perhaps the most widely known homosexual vampires come 
from the world of Anne Rice. The reason why many homosexuals, who feel ostracized by other vampire novels, flock to Rice's novels is because of the way that Rice writes her characters that grapple with same-sex attraction - particularly male same-sex attraction - through the eyes of the homosexual/homosocial characters themselves (Parker 50). The boundary, therefore, exists that homosexuality is okay amongst their own kind - vampires not intermingling with humans on a larger scale and not creating full familial ties. In Interview with the Vampire, the familial bond disrupts the homosocial bond between Lestat and Louis, demonstrating how the bite can be painful and destructive (Rice 100). Gilda uses the same vampiric bite to create her family and while Gilda's biting may not be consensual in most cases, it is healing rather than traumatizing, adding to the queerness of the activity.

Even though The Gilda Stories is not an entirely new way of exploring vampires, it is one of the first examples of a homosexual vampire character being written as redeemable. Gomez takes on the task of representing largely marginalized groups through vampires by using stereotypes to write a recognizable monster then crossing boundaries to make the stereotypes pointless. This is similar to Rice's approach to minorities in vampirism, but with a key intersectionality between race, sexuality, and gender (a black-lesbian-female lead) that Rice lacks in her most popular tales. Through this inclusivity, Gomez is able to highlight the struggle of Gilda fighting to fit in — whether it be due to racism, sexism, or homophobia — throughout The Gilda Stories in a way that other vampire stories only touch on metaphorically.

The duality of vampires can be seen in the very definition of gothic monster novelsgothic fiction being a narrative used to invoke both fear and desire (Halberstam 125). This can be seen as an "erotic anxiety and corrupt desire" (Parker 29). Monsters can destroy or deconstruct cultural boundaries without overstepping in a way humans, particularly those who are represented by monsters in the first place, cannot. This is no wonder Jewelle Gomez and those like her who are living through systemic racism, sexism, and homophobia would create a story to smash those boundaries superimposed by society as a whole.

Gilda's character relies on her relationship with other women in a way that the patriarchal society she lives in hates. Her interactions with other women are fueled by their vampiric nature. Her vampiric birth in the first place is due to the first Gilda - not only in biting this Gilda but through saving a nameless child, after the child was found on her property, and helping the child remain a runaway slave. Once she is turned, Gilda uses her powers to see into the minds of those she is drinking from or those she wants to be close to. Part of Gilda's character growth is to make sure that she does not stay too attached, or take too much, from each character she encounters, which is the opposite of what vampire novels, such as Dracula, have been grappling with since their conception.

In the beginning of Gilda's undead narrative, following her queer birth from two mothers, Gilda turns toward her own monstrosity as a way of gaining freedom from society. Specifically, she is no longer enslaved by white people, no longer reliant on others' sources of income to live, and no longer bound by living only through passed down bloodlines. Gilda becomes capable of experiencing the world in a way she never would have, had she remained human, all while becoming more empathetic towards others and arguably more human throughout the novel. Her outward appearance, however, holds her back throughout history as presented in the novel. 
Throughout The Gilda Stories, Gilda is visibly an alien threat to her societies due, not only to her sexuality, but to her race and gender as well (Parker 24). These factors add to the freedom that Gilda gains at night, being able to tap into people's prejudices and help them learn to be more compassionate towards other people (Gomez 123). Through her writing, Gomez is able to utilize Gilda and her narrative to realistically describe the oppression of minorities to those who do not understand and offers comfort to those who do know what it is to be demonized.

Gomez talks in her foreword for The Gilda Stories about creating her character, Gilda, as a revolutionary figure in the world of vampires. Gilda breaks social taboos, such as killing yet not dying, herself, while maintaining her more virtuous character traits that allow the reader to sympathize with her struggle. During her natural life, Gilda escapes enslavement with the help of other women around her. It is not until after her "death", however, that she gains the power that she utilizes throughout the novel (Gomez XII).

Gomez writes about Gilda, "Throughout her journey she tries to hold on to her humanity and help others to find theirs" (XII). This dynamic of the vampire being more human than the humans she encounters - the way that Gilda chooses to give even though she has the choice to just take-cements the barrier-breaking Gilda performs throughout the entire story.

The vampire in a queer sense was crafted by heterosexuals not to break boundaries, but as a way to enforce those already established. In this way, Gomez's twist on the vampire genrereflective of her own experiences as a black lesbian-was a revolutionary cultural shift of vampiric norms. In her own words, Gomez mentions how her story, in its earliest stages, was deemed "politically" wrong and even damaging to the black lesbian community (XIII). A black woman representing an already marginalized group as the monsters that society suspected they were was a risk. However, the risk has paid off. Thirty years later, homosexuals still find a sense of escape in her novel.

That escape comes, in part, to the audience's ability to connect to monsters as protagonists through the creation of a fantastical "other" self: a monster with which the reader identifies, at least in part, to the point where the monster is not the scary character of the novel (Cohen 24). Through claiming the monster as an "other" self, there is a shift from the monster being bad and abnormal to the monster being just as human — if less restrained - as the rest of the people in society. Therefore, Gomez's use of a vampire as a protagonist works: because readers can find themselves in Gilda - an "other" with a relatable place in the whole of humanity - they (the monster and the reader) become less the "other" and more a part of the whole.

Through a reclamation of the vampire identity in The Gilda Stories, Jewelle Gomez is able to start a dialogue surrounding the demonization of homosexuality, particularly of lesbians, in a way that owns up to stereotypes yet breaks boundaries. By creating a black, lesbian vampire who only grows to be more human after coming out of the coffin, Gomez is able to appeal to readers of all races and sexualities, but more importantly, she is able to affirm the existence of the "vampiric" minorities in society who have felt repressed for so long. Gomez's vampire is the monster who is able to break boundaries, specifically those set up by an oppressive society that wants the monster to stay strictly inside of its labeled boxes. The Gilda Stories can be used as a focal point for discussion of important lesbian feminist issues through its feminized focus on 
blood in a vampire novel, with how Gilda's character is situated in vampiric sexuality, and with how through Gilda, Gomez flips racial and gendered stereotypes for barrier release. It turns out that female homosexuals and vampires have much in common indeed!

Works Cited

Case, Sue-Ellen. “Tracking The Vampire." Feminist and Queer Performance: Critical Strategies, Palgrave Macmillan, London, UK, 2008, pp. 66-85.

Cohen, Jeffery Jerome, and L Andrew Cooper. "Monster Culture (Seven Theses).” Monsters, edited by Brandy Ball Blake, Fountainhead Press, 2012, pp. 11-33.

Gomez, Jewelle. The Gilda Stories: 25th Anniversary Edition. City Lights Publishers, 1991.

Halberstam, Judith, and L Andrew Cooper. "Parasites and Perverts: An Introduction to Gothic Monstrosity." Monsters, edited by Brandy B Blake, Fountainhead Press, 2012, pp. 123138.

Paker, Kendra R. Black Female Vampires in African American Women's Novels, 1977-2011: She Bites Back. Lexington Books, Lanham, Maryland, 2019, pp. 1-100.

Rice, Anne. Interview with the Vampire, Ballantine Books, New York, New York, 1967, pp. 100. 